\title{
INTRAPLEURAL HAEMORRHAGE IN ARTIFICIAL PNEUMOTHORAX
}

\author{
BY \\ JAMES T. HAROLD \\ From the Brompton Hospital, London
}

(RECEIVED FOR PUBLICATION APRIL 4, 1951)

Intrapleural haemorrhage is a serious complication of artificial pneumothorax (A.P.), sometimes endangering life and often leading to obliterative pleurisy and loss of the A.P. It is the purpose of this paper to discuss its causes, incidence, pathology, treatment, and effect on the A.P., on the basis of a study of the records of 37 cases in which intrapleural haemorrhage of not less than one pint $(600 \mathrm{ml}$.) occurred after refilling the A.P. or after thoracoscopy at the Brompton Hospital between 1939 and 1949.

\section{INCIDENCE}

Six of these cases followed A.P. refills, of which approximately 180,000 were given at the hospital during the relevant period, giving an incidence of approximately one in 30,000 refills. An incidence of one haemothorax per 2,500 A.P. refills over three years was quoted by Miller and Rinkel (1947). In order to restrict the present series to cases of severe haemorrhage, only those from which at least $20 \mathrm{oz}$. of blood or " heavily blood-stained fluid" were aspirated are included. Such criteria, if applied to the cases of Miller and Rinkel, would exclude four of their cases, leaving a comparable incidence of one in 5,000 refills.

The incidence of haemothorax following adhesion section at the Brompton Hospital was estimated by examining 814 patients having adhesion section between 1939 and 1949, performed by surgeons and trainees. Haemothorax requiring aspiration of at least $20 \mathrm{oz}$. (600 ml.) of blood or heavily blood-stained fluid occurred 31 times, representing an incidence of $3.9 \%$. There were a further 39 cases in which the volume of blood aspirated was between 10 and $20 \mathrm{oz}$. (300-600 ml.), and it is probable that many smaller haemothoraces occurred.

The incidence of haemothorax following thoracoscopy and adhesion section necessarily varies with the skill of the surgeon and the number of operators included in the series. Summation of the British series of Brock (1938), Edwards, Penman, and Logan (1944), Laird (1945), Watt (1947), and Wollaston (1947) gives a total of nearly 2,500 operations for adhesion section: the incidence of haemothorax of variable size was $3.5 \%$. Similarly, the combined American series of Graham, Singer, and Ballon (1935), Newton (1940), Goorwitch (1944), and Day, Chapman, and O'Brien (1948) cover more than 8,000 operations for adhesion section: the incidence of haemothorax of variable size was $4.3 \%$. 


\section{Aetiology}

Although haemorrhage into an A.P. is most frequent after instrumentation, it may be spontaneous. Spontaneous haemorrhage results from rupture of a tuberculous cavity or a non-tuberculous bulla ; in either case bleeding may arise directly from vessels at these sites, but it is more frequent from a vascularized adhesion secondarily ruptured by raised intrapleural tension. Spontaneous haemothorax during maintenance of an A.P. has been described by Jacob (1927), Bernard, Baron, and Valtis (1927), Luzzatto-Fegiz (1929), and Fossati and Boccia (1929), but when the bleeding occurs in close relation to thoracoscopy or A.P. refill it may be impossible to determine whether the bleeding is traumatic or spontaneous. Spontaneous haemothorax occurring after abandoning an A.P. has been described by Jacob (1927), Bernard and others (1927), Cordier and Levet (1931), and Korol (1936), and has been reviewed by Hurst and Epstein (1937).

Haemothorax after instrumentation may occur at the time of A.P. induction, after A.P. refills, or after thoracoscopy for division of adhesions: bleeding may arise from direct damage to a blood vessel or indirectly from increased intrapleural pressure and rupture of a vascularized adhesion.

Vessels particularly liable to bleed include the intercostal vessels, the lateral branch of the internal mammary artery (Cleland, 1948), intra-pulmonary vessels, vessels within adhesions or pleural symphyses, or vessels of the subpleural plexus. While any of these may cause brief haemorrhage, it is believed that severe continued bleeding is unlikely to result from damage to vessels within the lung, since wartime experience of traumatic haemothorax has shown that even severe pulmonary lacerations rarely cause continued bleeding. Miller and Rinkel (1947) suggested that local pain at the time of an A.P. refill indicated arterial wall damage, and chest wall bruising has been suggested as being of localizing value justifying intercostal ligation in some cases of haemothorax. Although chest wall bruising is not uncommon even after uncomplicated refills, it was noted in none of the six cases of the present series where bleeding followed an A.P. refill and intercostal ligation was never attempted.

Thoracoscopy is well recognized as the commonest cause of bleeding into an A.P. Slight bleeding before the thoracoscope is withdrawn is common and is usually controlled uneventfully. If bleeding begins after the thoracoscope has been withdrawn, and is not massive and acute, diagnosis may be difficult. A fluid level is often seen on radiographs taken after thoracoscopy and adhesion section: it was seen in approximately $45 \%$ of the combined series of Brock (1938), Laird (1945), Edwards and Lynn (1939), Edwards and others (1944), Watt (1947), and Wollaston (1947). In most institutions fluid is not sampled unless present in appreciable amounts, consequently this figure may include cases of an unrecognized small haemothorax.

The Natural History of Haemothorax.-The fate of blood in the pleural space is becoming better understood. Leblanc and Trousseau (1834) demonstrated that blood injected into the pleural cavity of horses always clotted but was later absorbed. Denny and Minot (1916) showed that, although the fluid which remained after clotting resembled whole blood, it contained only serum and cells. Bradford and Elliott (1915) described the constituents of the three different types of fluid which might result, depending on whether clotting was immediate and massive or slow 
with fragmentation and defibrination. Kato (1930) doubted whether intrapleural blood clotted, and suggested that the pleural exudate might contain an anticoagulant ; this suggestion has not been confirmed by subsequent workers. The clotting and subsequent fate of intrapleural blood was investigated by Sandison and Elkin (1933), who injected blood and clots into the pleural cavity of dogs and found that quantities of blood between $150 \mathrm{ml}$. and $500 \mathrm{ml}$. had been completely absorbed when the chest was opened 24 hours or more after injection. Simultaneous injections of air made clotting more likely and seemed to delay absorption. When clotted blood was placed in the pleural cavity in amounts between $100 \mathrm{ml}$. and $130 \mathrm{ml}$. absorption followed, but in amounts of $500 \mathrm{ml}$. the clot failed to absorb and an empyema followed. As a result of their experiments they concluded that the pleura was capable of complete and rapid absorption of small amounts of blood or blood clot without complication.

The 1939-45 war encouraged further work on the fate of intrapleural blood, and Barrett (1945) emphasized that in traumatic haemothorax there was some clotting in every case, that blood in the pleural space acted as a foreign body causing a serous effusion, and that the deposition of fibrin on the pleura began soon after wounding and was a serious complication which frequently resulted in respiratory crippling later. Sellors (1945) examined the fluid of more than 70 cases of traumatic haemothorax at daily intervals and showed that, while the haemoglobin concentration fell rapidly after the third day, simultaneously the fibrinogen content began to rise steeply so that at the end of the first week it became greater than that of normal blood. These changes resulted from the secondary effusion caused by the presence of blood in the pleural cavity. Sellors noted that its accumulation might be so rapid that the resulting signs of tension might be misinterpreted as evidence of further bleeding and cause the erroneous postponement of further aspirations. As a result of this secondary effusion the intrapleural fluid is again able to clot during the second week, a process described as " secondary clotting." Melick and Spooner (1945) showed experimentally that the pleural effusion contained no anticoagulant property, that early clotting occurred inevitably in every case of haemothorax, and that the fluid which remained after primary clotting was unable to clot owing to a deficiency of fibrinogen: they confirmed that small amounts of injected blood or clots were spontaneously absorbed without complication or adhesions.

The possible sequence of events which may follow bleeding into an A.P. may be summarized as follows.

1. Primary massive clotting may occur soon after bleeding has begun, but this occurs rarely: gradual bleeding limited by adhesions with immobile chest contents are the common predisposing factors.

2. Should massive clotting not occur, then primary clotting follows inevitably in every case, but the clot is rapidly fragmented and dispersed by respiratory and cardiac movements.

3. Immediately after primary clotting the fluid which remains resembles blood but cannot clot, having lost its fibrinogen.

4. Because blood in the pleural cavity acts as a foreign body, a reactionary effusion occurs reaching a maximum in three days: the resulting rise in fibrinogen 
concentration makes secondary clotting possible in the second week. Secondary clotting can therefore be prevented by early aspiration.

\section{TREATMENT}

A consideration of the events which occur when blood enters the pleural space makes it clear that the pleural space should be emptied at an early opportunity and kept dry. The aim is to reduce foreign matter to a quantity which the pleura can spontaneously absorb; and to reduce pleural exudation and so preclude secondary clotting. Thus the first three days are vital, and the risk of secondary clotting is reduced by adequate aspiration during this period. It would be of value to determine whether early and repeated aspiration gives better results than a less vigorous policy, but the completeness of aspiration can only be determined by post-aspiration radiographs, which were not available in all cases of the present series. Therefore the policy of aspirations must be based on the experimental work already described, supported by the clinical observation that small haemothoraces must occur frequently and are spontaneously absorbed without complication.

Fear of restarting haemorrhage by lowering intrapleural pressure by early aspiration has frequently been voiced. Thus Boland (1929) advised deferring aspiration of traumatic haemothoraces for 48 hours, and Head (1937) considered that aspiration should only be performed when the systolic blood pressure falls dangerously low.

Recent experience has led opinion in the opposite direction. Thus, although a raised intrathoracic pressure might check bleeding from the lung, Barrett (1945) pointed out that such bleeding was of brief duration and that bleeding from any other source was unlikely to be restarted by early aspiration unless an extremely low pressure was left, and there was considerable danger of fibrinization of the pleura if blood was allowed to remain in the pleural cavity. Miller and Rinkel (1947) advocated immediate aspiration of haemothoraces following A.P. refill, and this is now the usual practice. Such aspirations should be frequent and fearless, and a second needle under manometric control ensures that final intrapleural pressures are not dangerously lowered.

With regard to the frequency and quantity of aspirations a conservative policy has been recommended by Sandison and Elkin (1933), Hurst and Epstein (1937), and Cato and Norman (1940), while those who advocate a more aggressive aspiration policy include Barrett (1945), Sellors (1945), Miller and Rinkel (1947), and Ogilvie (1950). The changes which occur after intrapleural haemorrhage point clearly to the need for emptying the pleural cavity as soon as the patient's condition permits. There should be radiographic evidence of emptying, and if daily radiographs demonstrate reaccumulation aspiration should be performed immediately. With blood transfusions and control of pressures there is no limit to the quantity which may be removed; one patient in the present series had 5 pints $(3,000 \mathrm{ml}$.) aspirated at one operation and a total of 8 pints $(4,800 \mathrm{ml}$.) in the first 48 hours after bleeding following a refill.

\section{Clotted Haemothorax}

Fragmented primary clot sometimes hinders early aspiration through a needle, but if the pleural cavity is not kept dry and pleural exudation leads to secondary clotting in the second week, further needle aspirations are often impossible and 
other measures must be employed to empty the pleural cavity. To determine the frequency and the treatment of clotted haemothoraces in the present series, nine cases submitted to thoracoscopy or thoracotomy were further examined. Thoracoscopic aspiration was performed in seven patients: three of these later had a thoracotomy. In three of the seven patients no mention was made of needle aspirations having been hindered by clots. In the first of these cases thoracoscopy was performed on the second day after adhesion section although clots had not interfered with simple aspiration ; it may be deduced that early thoracoscopy was carried out to localize the bleeding point, but none was identified. In the second, thoracoscopy was performed 32 days after adhesion section because a fibrinous mass adherent to the apex of the lung was evident in the radiograph. In the third, $26 \mathrm{oz}$. $(780 \mathrm{ml}$.) of blood were aspirated through a needle on the first and fifth day after adhesion section, and $64 \mathrm{oz}$. $(1,920 \mathrm{ml}$.) removed through the thoracoscopic cannula on the sixth day apparently without any difficulty in aspirating through a needle. Thus, of the seven cases submitted to thoracoscopy, there remain four in which clotting seriously interfered with simple aspirations, representing an incidence in the whole series of approximately $9 \%$. In two of these four cases thoracoscopy was followed by further simple aspirations and resulted in an unaffected A.P., but, in the remaining two, clots persisted despite thoracoscopy, and thoracotomy was performed ; in both the A.P. was completely lost. In these four cases dry taps were encountered on the seventh, sixth, fifth, and tenth days respectively after bleeding started, and the average day on which thoracoscopy was undertaken for clotted haemothorax was the eighth after bleeding began; this agrees with experimental work showing the rise in fibrinogen content at this time.

Five patients underwent thoracotomy after previous aspiration in all and thoracoscopy in three. An examination of the records of these patients shows that early thoracotomy was performed in two cases within 48 hours in the hope of localizing the bleeding point, but in neither case was it identified and the A.P. was lost in both. A further case was explored, probably for the same reason: clots had not hindered simple or thoracoscopic aspirations, and thoracotomy was performed on the second day immediately after the successful removal of $40 \mathrm{oz}$. of blood through a thoracoscope. Thus there were two cases $(5 \%$ of the whole series) in which thoracotomy was performed because clotting interfered with simpler methods of aspiration.

Before considering operative measures for treating a clotted haemothorax, mention must be made of the use of liquefying enzymes derived from haemolytic streptococci (Tillett, Sherry, Christensen, Johnson, and Hazlehurst, 1950 ; Sherry, Tillett, and Read, 1950 ; Gauld and Harold, 1950). These enzymes were described by Tillett and Garner (1933), and concentrated, purified, and analysed by Christensen (1945) and Sherry, Tillett, and Christensen (1948); they have been named streptokinase and streptodornase, the former liquefying fibrin and the latter nucleoprotein. When injected intrapleurally the enzymes cause liquefaction of the clotted haemothorax and a severe pleural effusion. A brief febrile reaction generally accompanies these changes after which simple aspirations are again possible and are repeated until the pleural cavity is dry. The enzymes may have to be injected on two or three occasions and in different sites before complete liquefaction takes place. The results of treatment have so far been favourable. Sherry, Tillett, and 
Read (1950) describe the prompt clearing of nine out of 11 uninfected traumatic haemothoraces, and Gauld and Harold (1950) report the successful treatment of a large clotted haemothorax following an A.P. refill. Enzymatic liquefaction is therefore the treatment of choice in clotted haemothorax. Neither lung damage nor further bleeding caused by enzymatic action has so far been encountered in the 34 cases reported.

Evacuation of clotted haemothoraces through a thoracoscopic cannula was used 20 times by Moore and Watt (1947) in treating 40 haemothoraces following adhesion section. In the present series this procedure was employed for the same purpose in four out of 37 cases. If simple aspirations become impossible after one week and streptokinase is not available, then aspiration through a thoracoscopic cannula should be carried out and good results may be expected.

If clot remains in the pleural cavity despite simple and thoracoscopic aspiration, thoracotomy and clot removal should be undertaken. It is seen that this measure was used in only two out of 37 cases in the present series and in both cases the A.P. was lost.

\section{Identification of the Bleeding Point}

In cases of continued bleeding attempts to identify the bleeding point may be suggested. Thus thoracoscopy for continued bleeding was advocated by Cordier and Levet (1931), Jones and Gilbert (1936), Korol (1936), and others. In the present series thoracoscopy was performed in two patients for this purpose and in neither was a bleeding point identified. Korol (1936), Rubin and Rubin (1947), and others have advised thoracotomy as a means of localizing the bleeding point. Three patients in the present series underwent early thoracotomy for the same purpose and in none was a bleeding point identified: similar failures are described by Hurst and Epstein (1937) and Day and others (1948). In the light of this experience thoracoscopy and thoracotomy have little place in the early treatment of haemothorax complicating A.P. However severe or continued the bleeding, it is likely to cease spontaneously, and these measures carry risks in patients who are often critically ill. They offer little hope of identifying and treating the bleeding point.

Early decortication of traumatic clotted haemothoraces became widely practised in chest centres during the 1939-45 war, but its use in A.P. cases involves other issues. First, preservation of the A.P. is desired in most cases for subsequent treatment of the underlying tuberculous lung; and secondly, should it be decided that loss of the A.P. is inevitable, decortication may carry serious risk in a patient with active pulmonary tuberculosis. Pleural decortication was performed on one patient three months after the bleeding, but his A.P. was no longer essential, having been induced 18 months previously for minimal apical infiltration. Tuttle, Langston, and Crowley (1947) and Samson and Burford (1947) advised a delay of three to five weeks before decorticating a traumatic haemothorax on the grounds that earlier operation was difficult because adhesions were friable, and later operation was difficult because adhesions were tough. Ogilvie (1950) concluded that decortication of a traumatic haemothorax was inadvisable before the fourth week, so that the consideration of decorticating clotted haemothorax in A.P. should in no way interfere with the policy previously described. Although fibrothorax may in later years cause an unpredictable degree of respiratory disability, it may nevertheless provide 
useful control of the underlying tuberculosis, and decortication can, if indicated, be performed years later with less risk as was shown by Gordon and Welles (1949).

\section{Results of TReatment}

Successful treatment of haemothorax in A.P. must be partly measured by the survival of a useful A.P., but references to this aspect of treatment are few, and there is wide variation in the criteria adopted for the size of the haemothorax and for the follow-up and assessment of the surviving A.P. The details of 147 haemothoraces of variable size described by six authors are given in Table I with special reference to the effect on the A.P.

TABLE I

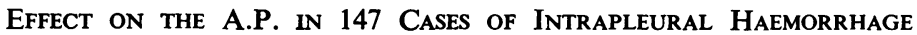

\begin{tabular}{|c|c|c|c|c|c|c|c|}
\hline \multirow[b]{2}{*}{ Author } & \multirow{2}{*}{$\begin{array}{l}\text { No. } \\
\text { of } \\
\text { Cases }\end{array}$} & \multirow[b]{2}{*}{ Aetiology } & \multirow[b]{2}{*}{ Size } & \multirow[b]{2}{*}{$\begin{array}{l}\text { Follow- } \\
\text { up }\end{array}$} & \multicolumn{3}{|c|}{ Effect on the A.P. } \\
\hline & & & & & Unaffected & $\begin{array}{c}\text { Partially } \\
\text { Lost }\end{array}$ & Lost \\
\hline $\begin{array}{l}\text { Hurst and Epstein } \\
\text { (1937) }\end{array}$ & 3 & Spontaneous & $?$ & $?$ & - & - & 2 died \\
\hline $\begin{array}{l}\text { Marcus and Pinner } \\
\text { (1946) }\end{array}$ & 7 & $\begin{array}{l}\text { Adhesion sec- } \\
\text { tion }\end{array}$ & 1 large & 6 months & - & - & 3 \\
\hline Wollaston (1947) & 42 & $\begin{array}{l}\text { Adhesion sec- } \\
\text { tion }\end{array}$ & $\begin{array}{l}\text { None } \\
\text { serious }\end{array}$ & ? & - & - & 1 \\
\hline $\begin{array}{l}\text { Moore and Watt } \\
\text { (1947) }\end{array}$ & 40 & $\begin{array}{l}\text { Adhesion sec- } \\
\text { tion }\end{array}$ & $\begin{array}{l}33 \text { over } \\
10 \mathrm{oz} .\end{array}$ & $\begin{array}{r}\text { Sanatorium } \\
\text { discharged }\end{array}$ & 6 & 16 & 18 \\
\hline $\begin{array}{l}\text { Miller and Rinkel } \\
\text { (1947) }\end{array}$ & 7 & A.P. refill & $\begin{array}{l}3 \text { over } \\
20 \mathrm{oz} .\end{array}$ & $\begin{array}{r}\text { Sanatorium } \\
\text { discharged }\end{array}$ & 3 & 1 & 3 \\
\hline $\begin{array}{l}\text { Day, Chapman, } \\
\text { and O'Brien } \\
\text { (1948) }\end{array}$ & 48 & $\begin{array}{l}\text { Adhesion sec- } \\
\text { tion }\end{array}$ & 4 large & 0 & - & - & 1 \\
\hline
\end{tabular}

In the present series of 37 haemothoraces, in every case the volume of blood aspirated exceeded 1 pint, and the period of observation averaged one and a half years. To correlate therapeutic usefulness of the surviving A.P. with the nature of the underlying disease was impossible, and the A.P. was assessed by comparing radiographs before and as long as possible after the bleeding. Those A.P.s suffering no obliteration are described as unaffected, obliteration of more than half was described as lost, and obliteration of less than half was described as partially lost. Such an assessment is clearly not synonymous with the therapeutic efficiency of the A.P., neither could allowance be made for the risk of subsequent spontaneous obliteration, although in the six cases where bleeding followed an A.P. refill the mean time of its occurrence was four years after induction of the A.P. The number of cases is too small for statistical conclusions to be drawn, but may indicate the results which may be expected from the treatment of this emergency. The results obtained in the present series by all methods of treatment are shown in Table II, from which it is seen that, in 28 cases treated by simple aspirations alone, there was complete survival of the A.P. in 18, while a further eight suffered only partial obliteration. Of the whole series of 37 cases treated by all methods, the A.P. was unaffected in 20 and suffered only partial obliteration in a further 12 . 
TABLE II

Results of Treatment by Different Methods

\begin{tabular}{|c|c|c|c|c|}
\hline \multirow{2}{*}{ Treatment } & \multicolumn{3}{|c|}{ Effect on A.P. } & \multirow{2}{*}{ Total } \\
\hline & Unaffected & Partially Lost & Lost & \\
\hline All methods & 20 & 12 & 5 & 37 \\
\hline Simple aspirations only $\quad \ldots \quad \ldots$ & 18 & 8 & 2 & 28 \\
\hline Aspirations and thoracoscopy $\quad \ldots$ & 1 & 3 & 0 & 4 \\
\hline $\begin{array}{c}\text { Aspirations, thoracoscopy, and thora- } \\
\text { cotomy }\end{array}$ & 1 & 0 & 2 & 3 \\
\hline Aspirations and thoracotomy only & 0 & 1 & 1 & 2 \\
\hline
\end{tabular}

Severe bleeding and delay in starting aspirations are believed to prejudice endresults. Thus Miller and Rinkel (1947) found severe obliteration in all cases where aspiration was delayed 48 hours. Table III shows the effect on the A.P. in cases where delay in starting aspirations was greater or less than five days, and also the results obtained in cases where the volume of blood aspirated was greater or less than $50 \mathrm{oz}$.

It is seen from Table III that aspirations were started before the fifth day in all five cases which suffered total loss of the A.P. and that the incidence of obliteration was approximately the same whether the volume aspirated was greater or less than 50 oz. (1,500 ml.).

TABLE III

Effect on the A.P. in Cases of Delayed First Aspiration and of Large Volume

\begin{tabular}{|c|c|c|c|c|c|}
\hline \multirow{2}{*}{\multicolumn{2}{|c|}{ Cases }} & \multirow{2}{*}{ Total } & \multicolumn{3}{|c|}{ Effect on A.P. } \\
\hline & & & Unaffected & Partially Lost & Lost \\
\hline $\begin{array}{l}\text { Blood aspirated before the } 5 \text { th day } \\
\text { Blood aspirated after the } 5 \text { th day }\end{array}$ & \begin{tabular}{l|}
$\cdots$ \\
$\cdots$
\end{tabular} & $\begin{array}{r}32 \\
5\end{array}$ & $\begin{array}{r}16 \\
3\end{array}$ & $\begin{array}{r}11 \\
2\end{array}$ & $\begin{array}{l}5 \\
0\end{array}$ \\
\hline 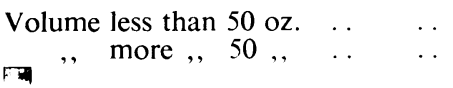 & $\begin{array}{l}\cdots \\
\cdots\end{array}$ & $\begin{array}{l}21 \\
16\end{array}$ & $\begin{array}{r}11 \\
9\end{array}$ & $\begin{array}{l}8 \\
4\end{array}$ & $\begin{array}{l}2 \\
3\end{array}$ \\
\hline
\end{tabular}

\section{SUMMARY}

During the years 193949,37 cases of severe intrapleural haemorrhage have occurred during A.P. therapy at the Brompton Hospital. The results obtained by different methods of treatment employed in these cases have been compared, and they suggest that the standard method of simple aspiration was satisfactory. They indicate the results which may be expected from this and other methods of treatment which may have to be employed. Factors generally held to be adverse, such as severe haemorrhage and delay in starting aspirations, did not significantly modify the results of treatment in this series and do not justify a poor prognosis. Deaths are rare, most cases do well, and a useful surviving A.P. is the rule. It is probable 
that attention to aspiration technique and the use of fibrinolytic enzymes will further reduce the number of failures in the treatment of this emergency.

I am grateful to Dr. Neville Oswald and to Dr. W. D. H. St.John Brooks for criticism and assistance in the preparation of this paper, and to the consultant staff of the Brompton Hospital for permission to study the results of treatment of their cases.

\section{REFERENCES}

Barrett, N. R. (1945). Lancet, 1, 103.

Bernard, L., Baron, L., and Valtis, J. (1927). Rev. Tuberc., Paris, sér. 3, 8, 465.

Boland, F. K. (1929). J. Amer. med. Ass., 93, 1716.

Bradford, J. R., and Elliott, T. R. (1915). Brit. J. Surg., 3, 247.

Brock, R. C. (1938). Brompton Hosp. Rep., 7, 81.

Cato, F. L., and Norman, W. D. (1940). Surgery, 7, 848.

Christensen, L. R. (1945). J. gen. Physiol., 28, 363.

Cleland, W. P. (1948). Thorax, 3, 127.

Cordier, V., and Levet, L. (1931). J. Méd. Lyon, 12, 139.

Day, J. C., Chapman, P. T., and O'Brien, E. J. (1948). J. thorac. Surg., 17, 537.

Denny, G. P., and Minot, G. R. (1916). Amer. J. Physiol., 39, 455.

Edwards, P. W., and Lynn, A. (1939). Brit. med. J., 2, 897.

Penman, A. C., and Logan, J. (1944). Ibid., 2, 270.

Fossati, V., and Boccia, D. (1929). Rev. sud-amer. Endocrinol., 12, 570.

Gauld, R. G., and Harold, J. T. (1950). Brit. J. Tuberc., 44, 77.

Goorwitch, J. (1944). J. thorac. Surg., 13, 223.

Gordon, J., and Welles, E. S. (1949). Ibid., 18, 337.

Graham, E., Singer, J., and Ballon, H. (1935). Surgical Diseases of the Chest. London.

Head, J. R. (1937). Surg. Gynec. Obstet., 65, 485.

Hurst, A., and Epstein, H. H. (1937). Quart. Bull. Sea View Hosp., 2, 155.

Jacob, P. (1927). Rev. Tuberc., Paris, sér. 3, 8, 594.

Jones, O. R., and Gilbert, C. L. (1936). Amer. Rev. Tuberc., 33, 165.

Kato, T. (1930). Jap. J. med. Sci., 81.

Korol, E. (1936). Amer. Rev. Tuberc., 33, 185.

Laird, R. (1945). Tubercle, Lond., 26, 149.

Leblanc, M. U., and Trousseau, A. (1834). J. Méd. vét., 5, 104.

Luzzatto-Fegiz, G. (1929). Policlinico (prat.), 36, 162.

Marcus, H., and Pinner, M. (1946). Amer. Rev. Tuberc., 54, 25.

Melick, D. W., and Spooner, M. (1945). J. thorac. Surg., 14, 461.

Miller, A. K., and Rinkel, L. R. J. (1947). Lancet, 1, 906.

Moore, W. E. D., and Watt, J. (1947). Tubercle, Lond., 28, 161.

Newton, H. F. (1940). Amer. Rev. Tuberc., 41, 22.

Ogilvie, A. G. (1950). Thorax, 5, 116.

Rubin, E., and Rubin, M. (1947). Diseases of the Chest, Philadelphia.

Samson, P. C., and Burford, T. H. (1947). J. thorac. Surg., 16, 127.

Sandison, J. C., and Elkin, D. C. (1933). Ibid., 2, 453.

Sellors, T. H. (1945). Lancet, 1, 143 .

Sherry, S., Tillett, W. S., and Christensen, L. R. (1948). Proc. Soc. exp. Biol., N.Y., 68, 179.

- and Read, C. T. (1950). J. thorac. Surg., 20, 393.

Tillett, W. S., and Garner, R. L. (1933). J. exp. Med., 58, 485.

Sherry, S., Christensen, L. R., Johnson, A. J., and Hazlehurst, G. (1950). Ann. Surg., 131, 12.

Tuttle, W. M., Langston, H. T., and Crowley, R. T. (1947). J. thorac. Surg., 16, 117.

Watt, J. (1947). Tubercle, Lond., 28, 158.

Wollaston, F. L. (1947). Lancet, 2, 424. 